PREPARED FOR THE U.S. DEPARTMENT OF ENERGY, UNDER CONTRACT DE-AC02-76CH03073

PPPL-3874

PPPL-3874

UC-70

Development of Compact Quasi-axisymmetric Stellarator Reactor Configurations

by

L.P. Ku, M. Zarnstorff, R.B. White, W.A. Cooper,

R. Sanchez, H. Neilson, and J.A. Schmidt

September 2003

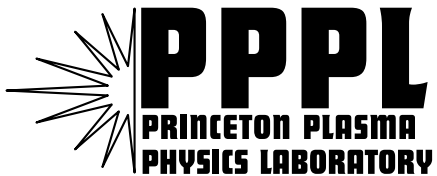

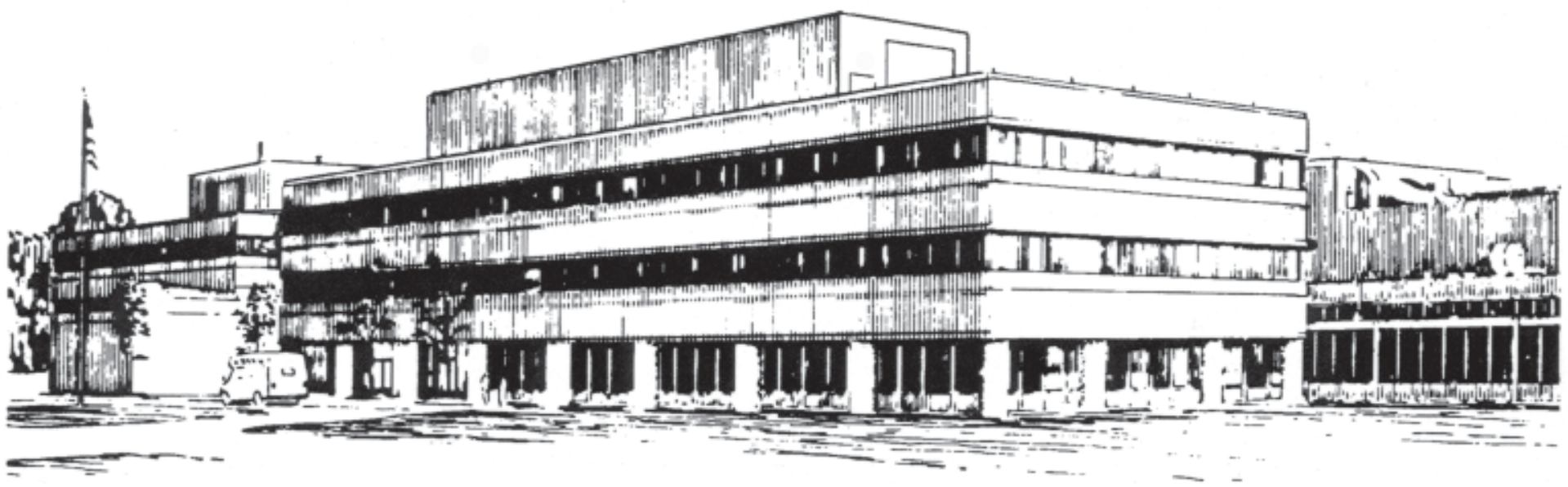

PRINCETON PLASMA PHYSICS LABORATORY PRINCETON UNIVERSITY, PRINCETON, NEW JERSEY 


\section{PPPL Reports Disclaimer}

This report was prepared as an account of work sponsored by an agency of the United States Government. Neither the United States Government nor any agency thereof, nor any of their employees, makes any warranty, express or implied, or assumes any legal liability or responsibility for the accuracy, completeness, or usefulness of any information, apparatus, product, or process disclosed, or represents that its use would not infringe privately owned rights. Reference herein to any specific commercial product, process, or service by trade name, trademark, manufacturer, or otherwise, does not necessarily constitute or imply its endorsement, recommendation, or favoring by the United States Government or any agency thereof. The views and opinions of authors expressed herein do not necessarily state or reflect those of the United States Government or any agency thereof.

\section{Availability}

This report is posted on the U.S. Department of Energy's Princeton Plasma Physics Laboratory Publications and Reports web site in Fiscal Year 2003. The home page for PPPL Reports and Publications is: http://www.pppl.gov/pub_report/

DOE and DOE Contractors can obtain copies of this report from:

U.S. Department of Energy

Office of Scientific and Technical Information

DOE Technical Information Services (DTIS)

P.O. Box 62

Oak Ridge, TN 37831

Telephone: (865) 576-8401

Fax: (865) 576-5728

Email: reports@adonis.osti.gov

This report is available to the general public from:

National Technical Information Service

U.S. Department of Commerce

5285 Port Royal Road

Springfield, VA 22161

Telephone: $1-800-553-6847$ or

(703) $605-6000$

Fax: (703) 321-8547

Internet: http://www.ntis.gov/ordering.htm 


\title{
DEVELOPMENT OF COMPACT QUASI-AXISYMMETRIC STELLARATOR REACTOR CONFIGURATIONS
}

\author{
L. P. Ku ${ }^{\mathrm{a}}$, M. Zarnstorff $f^{\mathrm{a}}$, R. B. White ${ }^{\mathrm{a}}$, W. A. Cooper ${ }^{\mathrm{b}}$, R. Sanchez ${ }^{\mathrm{c}}$, \\ H. Neilson ${ }^{\mathrm{a}}$, J. A. Schmidt ${ }^{\mathrm{a}}$ \\ ${ }^{a}$ Princeton Plasma Physics Laboratory, Princeton, NJ 08543-0451, USA \\ ${ }^{b}$ Centre de Recherches en Physique des Plasmas, Association Euratom-Suisse, Ecole \\ Polytechnique Federale de Lausanne, CRPP-PPB, Lausanne, Switzerland \\ ${ }^{c}$ Departamento de Fisica, Universidad Carlos III de Madrid, Madrid, Spain
}

\section{Introduction}

Stellarators with an underlying quasi-axisymmetric (QA) magnetic field structure have attracted intense interests in recent years. They hold the promise of being able to result in smaller devices at high $\beta$ that are passively stable to MHD perturbations. The vision of their reactor competitiveness, coupled with the advent of optimization techniques, has led to the development of NCSX [1], an experimental device now in the preliminary design phase. To further expand the effort, an ARIES Compact Stellarator (CS) project has recently been initiated. It is intended to examine the competitiveness and the critical issues of CS as power producing reactors. Our initial studies indicate that a $1 \mathrm{GW}(\mathrm{e})$ reactor based on the concept of quasi-axisymmetry of a major radius less than 8 meters may be realizable.

For a power-producing reactor, in addition to the high power density and MHD stability, there are other important parameters needing careful considerations. Chief among these are the loss of $\alpha$ particles, which affects the power balance and heat loads on the first wall, and the coil aspect ratio (the ratio of the major radius to the minimum separation between the plasma edge and the coil center), which is perhaps one the most important parameters determining the size and therefore the cost of a reactor. In addition, the quality of flux surfaces, the constraint of the limiting magnetic field in the design of super-conducting magnets, the impact of coil topology on remote maintenance, and the systems optimization of the cost of electricity, are also of critical importance. In this paper, we report the recent progress in our effort to extend the optimization of NCSX-like plasmas to minimize the loss of $\alpha$ particles.

The importance of $\alpha$ loss resulting from the breaking of axisymmetry has been realized for quite some time. Efforts to use various techniques to minimize their losses in the configuration design have been attempted. Gori et al. have used a Monte Carlo algorithm to minimize the loss of trapped alphas [2]. Subbotin et al. have tried both the method of maximizing the psuedosymmetry and the closing of J-contours [3]. We have examined various methods and find that the combination of directly minimizing the residues of the non-axisymmetric components of the magnetic spectrum together with maximizing the average resident times of the collisionless $\alpha$ 's of all classes provide a robust and efficient means to reduce $\alpha$ losses while at the same time maintaining the quasi-axisymmetry and the stability to the ideal, linear MHD modes in the configuration optimization. 


\section{Configuration Optimization and Alpha Loss Minimization}

Nuhrenberg et al. pioneered the stellarator configuration optimization [4]. In the development of NCSX, the efficiency of the optimization and the number of target and constraint functions were vastly improved and expanded. The increased efficiency is made possible by evaluating functions in parallel, either in the gradient calculations when the local gradient search algorithm is used or in the "fitness" calculations when the genetic or differential evolution algorithm is used. In addition to the optimization of plasma properties by varying the shape of the last closed magnetic surface (LCMS), direct optimization of plasma properties and parameters important for operational considerations (e.g. scrape-off layer thickness) and coil engineering (e.g. coil-coil spacing, bend radius, current density) can be executed simultaneously by representing coil structure as the state variables. This latter capability is extremely important since the "reverse engineering" to obtain a coil design using the first approach often results in degraded performance of the plasma. However, to understand how plasma shaping defines its properties, such as the $\alpha$ loss characteristic, optimizing configurations by varying the shape of the LCMS is an essential first step. It is this procedure that we have used in our initial quest of an optimized reactor configuration.

The optimizer we built allows multiple "goodness" functions that can be "plugged-in" as individual modules. These modules include parameters concerning the basic properties (such as the desired amount of external rotational transform, the magnetic shear, magnetic well depth), measures of MHD stability (such as external kinks, infinite-n ballooning), and figures of merit for transport (such as effective ripples, diffusion coefficient evaluations). In addition, we have newly implemented functions useful for addressing fast ion confinements. These include minimizing the "leakage" of J-contours and directly using the Monte Carlo procedure to maximize the resident times of collisionless $\alpha$ 's that would otherwise escape rather quickly. The latter is made possible by using a streamlined version of the guiding center code ORBIT-3D [5]. We note that by including only the collionless process the only parameters that would be affected by the "randomness" are the initial position and pitch angle of the particles. By using the same seed to start the Monte Carlo process, the random walks would be highly correlated in the gradient calculations and the resulting stochastic effect would be minimal in the determination of the direction of the steepest descent in the equilibrium parameter space. We find that the Monte Carlo approach is effective and robust even when restricted to a small sample size, a small cutoff lost fraction and a limited number of toroidal transits.

\section{Results and Discussion}

We have carried out configuration optimization to minimize alpha losses at $4 \%$ beta in a configuration subspace where the aspect ratio A ranges from 3 to 6.5 and the rotational transform $\imath$ spans from 0.3 to 0.7 at $\mathrm{s}=0.5$ (Here, $\mathrm{s}$ is the toroidal flux label). We examined configurations with 2,3 and 4 field periods. The $\mathrm{N}=1$ kink stability calculation was carried out by TERPSICHORE [6] with the highest poloidal perturbation mode 15 and toroidal perturbation mode 9,8 , and 11 for 2, 3 and 4-period devices, respectively, for a total of 91 modes in all cases. The infinite-n ballooning calculation was carried out using COBRA [7] along two field lines centered at $\phi=0$ and $\pi / 2$, where $\phi$ is the VMEC toroidal angle. VMEC [8] equilibria were mapped to the Boozer coordinates, retaining 15 poloidal modes and 9 toroidal modes in the ORBIT-3D 
calculation for the $\alpha$ losses. In the evaluation of initial collisionless losses, we used 1024 sample particles with a uniform pitch distribution at $s=0.5$. In each case, we required that both stability criteria be satisfied while alpha losses minimized to the extent possible. Once a configuration was found, we further carried out a complete $\alpha$ slowing down calculation for $0.258 \mathrm{~s}$, with a peaked $\left(\{1-\mathrm{s}\}^{8}\right)$ birth distribution and a parabolic background ion distribution. The field on axis was set at $5.5 \mathrm{~T}$ and the major radius was adjusted such that the total volume was $1000 \mathrm{~m}^{3}$ in all the cases. The sample size for these calculations was 4096.

A typical example of a 3 -field period, $A=6$ configuration is illustrated in fig. 1 . The configuration has an average elongation about 1.8 and triangularity 0.6 , comparable to those of the advanced tokamak configurations. In fig. 1 we also show the profiles of rotational transform for both the external component and the overall transform including the internal contribution from the bootstrap current. The three-dimensional shaping contributes more than $70 \%$ of the transform through the entire plasma, making the configuration stable to the vertical mode [9]. The harmonic contents in the magnetic spectrum are given in fig. 2. We see that the nonaxisymmetric residues are everywhere less than $1 \%$ of the main $m=0, n=0$ component. The overall $\alpha$ energy loss for this case is $\sim 10 \%$. The angular pattern of the losses is given in fig. 3 , where it is shown that the loss of high energy particles is concentrated in narrow bands, poloidally in the lower half of the plasma about $60^{\circ}$ from the midplane and toroidally at about the half-field period location.
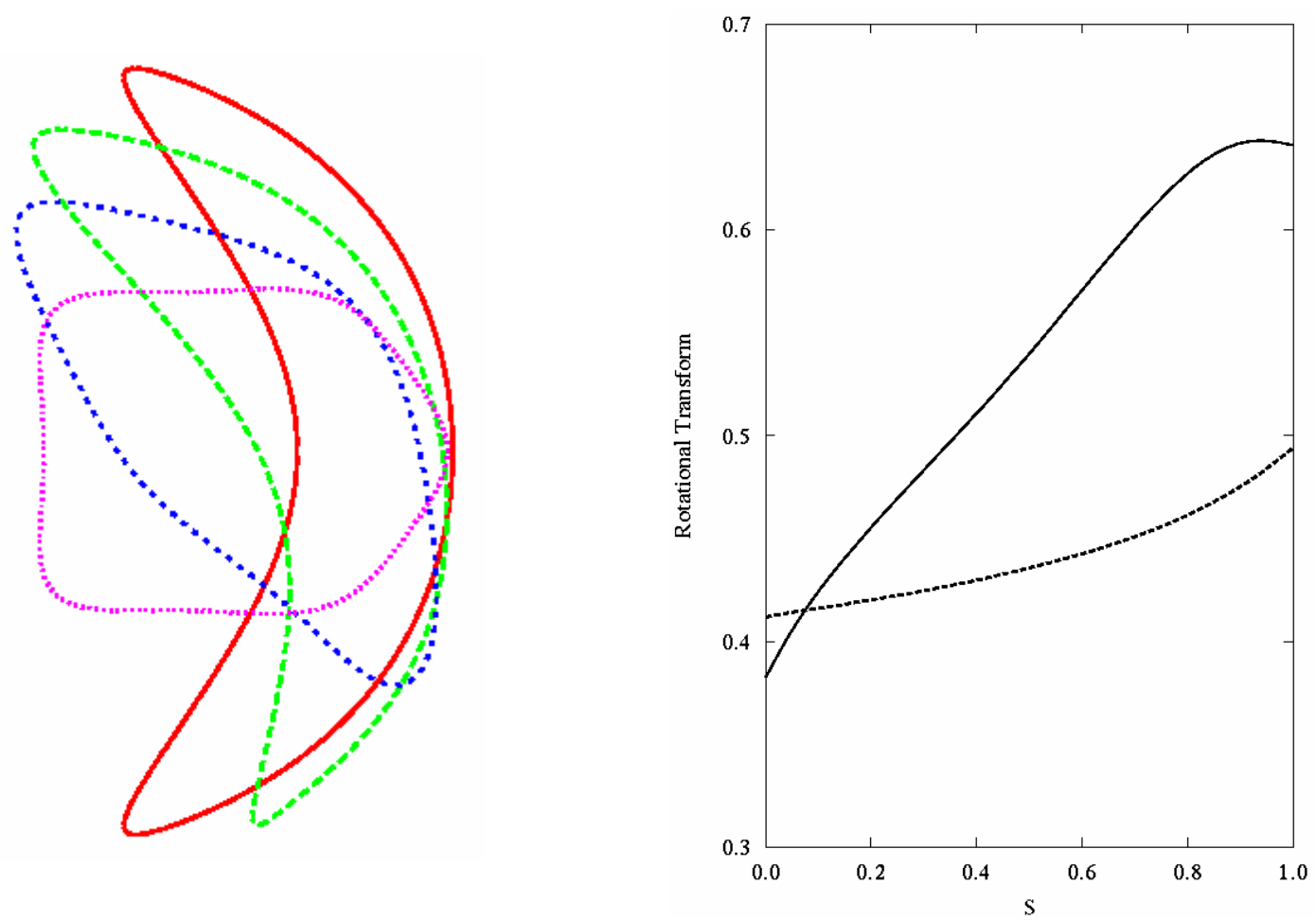

Fig. 1. An optimized, 3 -field period, $A=6$ configuration showing the LCMS in four equal toroidal cuts in half a period (left) and the rotational transform profiles as functions of the normalized toroidal flux s (right). The upper curve (solid) in the rotational transform is the total including the internal contribution from the bootstrap current at $4 \% \beta$. The lower curve (dash) is the transform due to the plasma shaping alone. 


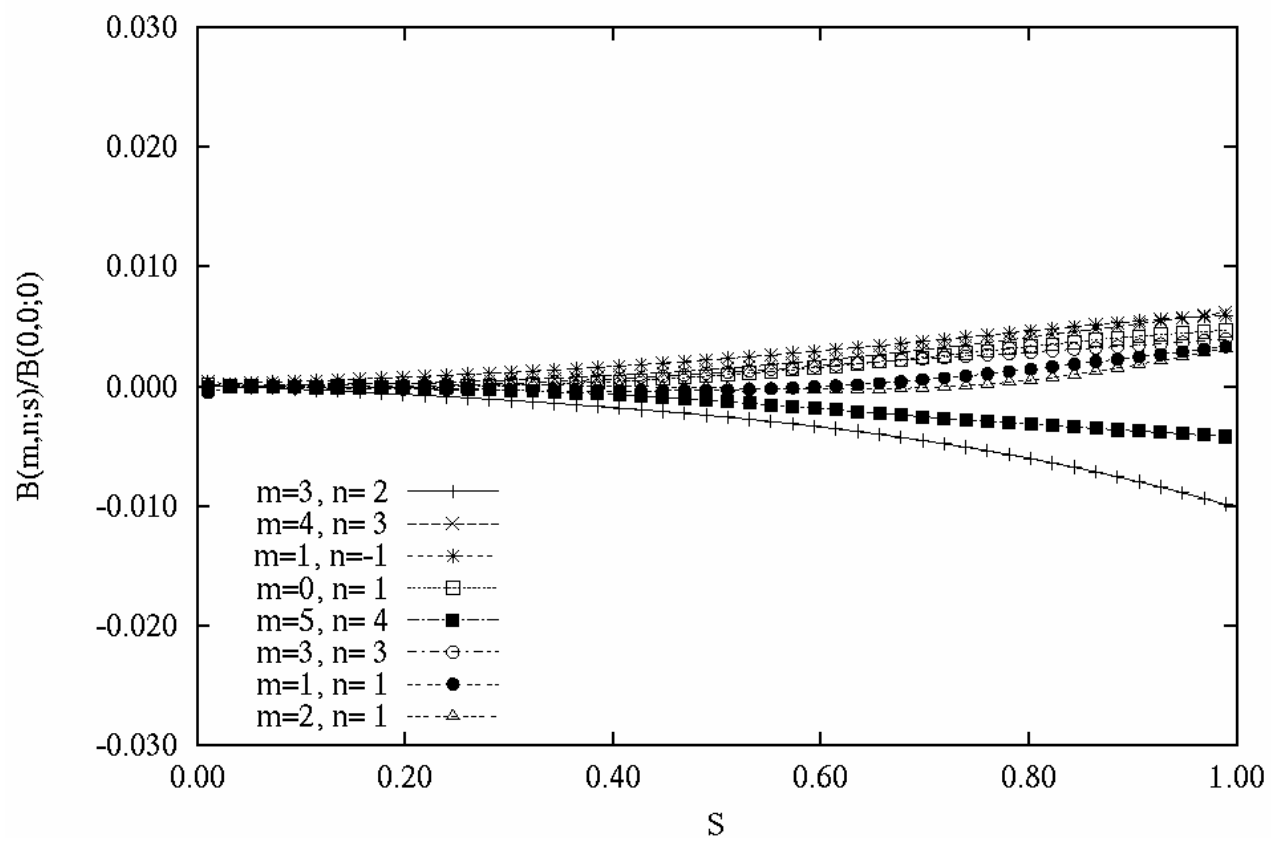

Fig. 2. Harmonic contents in the Boozer magnetic spectrum for the configuration given in figure 1 plotted as functions of the normalized toroidal flux. We display eight modes, where $\mathrm{m}$ is the poloidal mode number and $\mathrm{n}$ is the toroidal mode number.

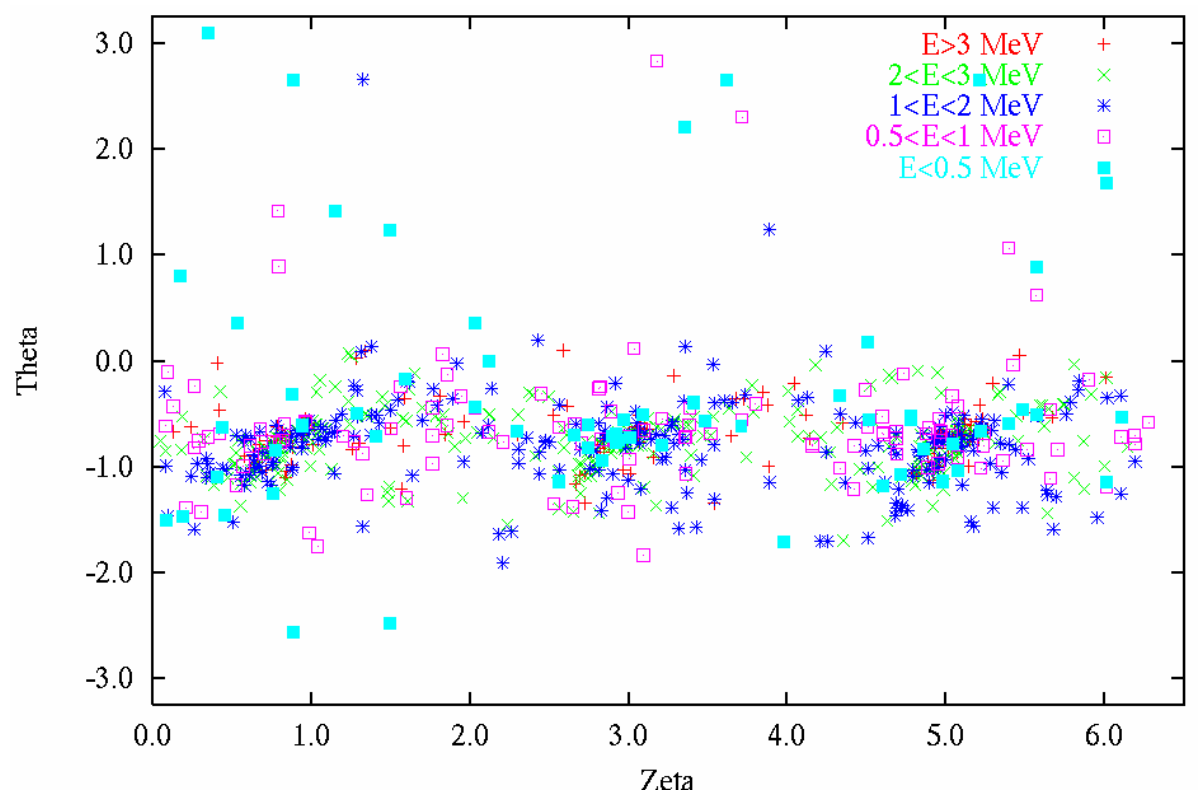

Fig. 3. Footprints of lost $\alpha$ on the LCMS for the configuration given in figure 1 . B=5.5 T, Volume $=1000 \mathrm{~m}^{3}$. Zeta and theta are toroidal and poloidal Boozer angles, respectively.

In this example configuration, although an excellent quasi-axisymmety is attained, the alpha loss is nevertheless non-negligible. Studies of the lost orbits, particularly the prompt losses, show that there are a number of initially passing orbits that become trapped and de-trapped, and 
for both the trapped and passing particles there are substantial radial drift involved, similar to those discussed by Mynick [10] and Goldston, White and Boozer [11]. Since the quasiaxisymmetry degrades towards larger radii, particularly components of high poloidal and toroidal numbers, the drift enhances the chance of $\alpha$ particles being ripple trapped and quickly lost. Whenever we tried to relax some of the other constraints to improve the $\alpha$ losses we inevitably find that the quasi-axisymmetry is also improved in the outer regions.

The search in the iota space also indicates that the alpha loss could be lowered at a given aspect ratio when the poloidal flux is increased. Indeed, we have obtained a 3-field period, aspect ratio 4.5 configuration in which the alpha loss is only $\sim 4 \%$ when the average rotational transform is raised to $\sim 0.65$. The higher rotational transform makes the stability to the external kinks harder to satisfy and, consequently, demands more plasma shaping, which may not be desirable from coil design point of view; however.

The best configuration ultimately depends on how well one can design coils, particularly coils with the lowest feasible coil aspect ratio. Our recent study [12] for a particular coil set for an aspect ratio 4.5 plasma indicated that there is a minimum coil aspect ratio below which the increased coil current and coil complexity will give rise to too high a field in the coil body, and above which the high coil current density due to the space limitation between coils and the plasma also gives rise to higher fields when a minimum required blanket and shield thickness $(\sim 1.1 \mathrm{~m})$ is imposed.

\section{Summary and Conclusions}

We have started to examine the reactor potential of quasi-axisymmetric stellarators with an integrated approach that includes systems evaluation, engineering considerations, and plasma and coil optimizations. In this paper, we summarize the progress made so far in developing QA configurations with reduced $\alpha$ losses while retaining good MHD stability properties. The minimization of $\alpha$ losses is achieved by directly targeting the collisionless orbits to prolong the average resident times. Configurations with an overall energy loss rate of $\sim 10 \%$ or less, including collisional contributions, have been found. To allow remotely maintaining coils and machine components in a reactor environment, there is a desire to simplify to the extent possible the coil design. To this end, finding a configuration that is optimized not only for the $\alpha$ confinement and MHD stability but also for the good coil and reactor performance, remains to be a challenging task.

\section{Acknowledgment}

This work was supported by the United States Department of Energy Contract DE-AC02-76CHO-3073. The authors would like to acknowledge contributions from other members of the ARIES compact stellarator team, particularly J. Lyon of ORNL, P. Garabedian of NYU, L. ElGuebaly of University of Wisconsin, T. K. Mau, F. Najmabadi, R. Raffray, X. Wang of UCSD, L. Bromberg of MIT, A. Turnbull of GA, and L. Waganer of Boeing High Energy Systems. 
[1] G. H. Neilson, M. Zarnstorff, L. P. Ku, et al., IAEA-CN-94/IC-1 19th International Atomic Energy Agency Fusion Energy Conference, Lyon, France, October 14-19 (2002).

[2] S. Gori, J. Nuhrenberg, R. Zille, S. Okamura, K. Matsuoka, 12th Int. Stellarator Workshop, Madison 1999. Also, Plasma Phys. Contr. Fus. 43, 137 (2001).

[3] A. A. Subbotin, M. I. Mikhailov, J. Nuhrenberg, et al., $28^{\text {th }}$ EPS Conference on Contr. Fusion and Plasma Phys. Funchal, June 18-22 (2001).

[4] J. Nuhrenberg, W. Lotz, S. Gori, Theory of Fusion Plasma (Varenna 1994), Editrice Compositori, Bologna 3 (1994).

[5] R. B. White and M. S. Chance, Phys. Fluids 27, 2455 (1984).

[6] D. V. Anderson, W. A. Cooper, R. Gruber, S. Merazzi, U. Schwenn, Scient. Comp. Supercomp. II, 159 (1990).

[7] R. Sanchez, S. P. Hirshman, J. C. Whitson, and A. S. Ware, J. Comp. Phys. 161, 589 (2000).

[8] S. P. Hirshman and J. C. Whitson, Phys. Fluids 26, 3553 (1983).

[9] G.Y. Fu, Phys. of Plasma, 7, No 4, 1079 (2000).

[10] H. E. Mynick, Phys. Fluids B 5, 1471 (1993).

[11] R. J. Goldston, R. B. White, and A. H. Boozer, Phys. Rev. Lett., 47, 647 (1981).

[12] L. P. Ku, 20 ${ }^{\text {th }}$ IEEE/NPSS Symposium on Fusion Engineering, San Diego, CA, October 1417 (2003). 


\section{External Distribution}

Plasma Research Laboratory, Australian National University, Australia

Professor I.R. Jones, Flinders University, Australia

Professor João Canalle, Instituto de Fisica DEQ/IF - UERJ, Brazil

Mr. Gerson O. Ludwig, Instituto Nacional de Pesquisas, Brazil

Dr. P.H. Sakanaka, Instituto Fisica, Brazil

The Librarian, Culham Laboratory, England

Mrs. S.A. Hutchinson, JET Library, England

Professor M.N. Bussac, Ecole Polytechnique, France

Librarian, Max-Planck-Institut für Plasmaphysik, Germany

Jolan Moldvai, Reports Library, Hungarian Academy of Sciences, Central Research Institute for Physics, Hungary

Dr. P. Kaw, Institute for Plasma Research, India

Ms. P.J. Pathak, Librarian, Institute for Plasma Research, India

Ms. Clelia De Palo, Associazione EURATOM-ENEA, Italy

Dr. G. Grosso, Instituto di Fisica del Plasma, Italy

Librarian, Naka Fusion Research Establishment, JAERI, Japan

Library, Laboratory for Complex Energy Processes, Institute for Advanced Study, Kyoto University, Japan

Research Information Center, National Institute for Fusion Science, Japan

Dr. O. Mitarai, Kyushu Tokai University, Japan

Dr. Jiangang Li, Institute of Plasma Physics, Chinese Academy of Sciences, People's Republic of China

Professor Yuping Huo, School of Physical Science and Technology, People's Republic of China

Library, Academia Sinica, Institute of Plasma Physics, People's Republic of China

Librarian, Institute of Physics, Chinese Academy of Sciences, People's Republic of China

Dr. S. Mirnov, TRINITI, Troitsk, Russian Federation, Russia

Dr. V.S. Strelkov, Kurchatov Institute, Russian Federation, Russia

Professor Peter Lukac, Katedra Fyziky Plazmy MFF UK, Mlynska dolina F-2, Komenskeho Univerzita, SK-842 15 Bratislava, Slovakia

Dr. G.S. Lee, Korea Basic Science Institute, South Korea

Institute for Plasma Research, University of Maryland, USA

Librarian, Fusion Energy Division, Oak Ridge National Laboratory, USA

Librarian, Institute of Fusion Studies, University of Texas, USA

Librarian, Magnetic Fusion Program, Lawrence Livermore National Laboratory, USA

Library, General Atomics, USA

Plasma Physics Group, Fusion Energy Research Program, University of California at San Diego, USA

Plasma Physics Library, Columbia University, USA

Alkesh Punjabi, Center for Fusion Research and Training, Hampton University, USA

Dr. W.M. Stacey, Fusion Research Center, Georgia Institute of Technology, USA

Dr. John Willis, U.S. Department of Energy, Office of Fusion Energy Sciences, USA

Mr. Paul H. Wright, Indianapolis, Indiana, USA 
The Princeton Plasma Physics Laboratory is operated by Princeton University under contract with the U.S. Department of Energy.

\author{
Information Services \\ Princeton Plasma Physics Laboratory \\ P.O. Box 451 \\ Princeton, NJ 08543
}

Phone: 609-243-2750

Fax: 609-243-2751

e-mail: pppl_info@pppl.gov

Internet Address: http://www.pppl.gov 